\title{
Trade-offs between biodiversity and agriculture are moving targets in dynamic landscapes
}

\author{
Leandro Macchi ${ }^{1}$ (D) | Julieta Decarre ${ }^{2}$ | Andrea P. Goijman ${ }^{2}$ | Matías Mastrangelo ${ }^{3}$ | \\ Pedro G. Blendinger $^{1}$ | Gregorio I. Gavier-Pizarro ${ }^{2}$ | Francisco Murray ${ }^{4}$ | \\ María Piquer-Rodriguez $^{1}$ | Asunción Semper-Pascual ${ }^{5}$ (D) | Tobias Kuemmerle ${ }^{5,6}$
}

${ }^{1}$ Instituto de Ecología Regional (IER), CONICET - Universidad Nacional de Tucumán, Tucumán, Argentina; ${ }^{2}$ Instituto de Recursos Biológicos (IRB-CIRN), Instituto Nacional de Tecnología Agropecuaria (INTA), Buenos Aires, Argentina; ${ }^{3}$ Grupo de Estudios de Agroecosistemas y Paisajes Rurales (GEAP), CONICET - Universidad Nacional de Mar del Plata, Buenos Aires, Argentina; ${ }^{4}$ Agencia de Extensión Rural San Luis, Instituto Nacional de Tecnología Agropecuaria (INTA), San Luis, Argentina; ${ }^{5}$ Geography Department, Humboldt-Universität zu Berlin, Berlin, Germany and ${ }^{6}$ Integrative Research Institute on Transformations of Human-Environment Systems (IRI-THESys), Humboldt-Universität zu Berlin, Berlin, Germany

Correspondence

Leandro Macchi

Email: leandromacchi@gmail.com

\section{Julieta Decarre}

Email: decarre.julieta@inta.gob.ar

\section{Funding information}

Alexander von Humboldt-Stiftung; INTA Natural Resources National Programme, Grant/Award Number: PNNAT 1128053 and 1128052; Fondo para la Investigación Científica y Tecnológica, Grant/Award Number: PICT 2006-1693; Deutsche Forschungsgemeinschaft, Grant/Award Number: KU 2458/5-1; Bundesministerium für Bildung und Forschung, Grant/Award Number: 031B0034A

Handling Editor: Guadalupe Peralta

\section{Abstract}

1. Understanding how biodiversity responds to intensifying agriculture is critical to mitigating the trade-offs between them. These trade-offs are particularly strong in tropical and subtropical deforestation frontiers, yet it remains unclear how changing landscape context in such frontiers alters agriculture-biodiversity trade-offs.

2. We focus on the Argentinean Chaco, a global deforestation hotspot, to explore how landscape context shapes trade-off curves between agricultural intensity and avian biodiversity. We use a space-for-time approach and integrate a large field dataset of bird communities (197 species, 234 survey plots), three agricultural intensity metrics (meat yield, energy yield and profit) and a range of environmental covariates in a hierarchical Bayesian occupancy framework.

3. Woodland extent in the landscape consistently determines how individual bird species, and the bird community as a whole, respond to agricultural intensity. Many species switch in their fundamental response, from decreasing occupancy with increased agricultural intensity when woodland extent in the landscape is low (loser species), to increasing occupancy with increased agricultural intensity when woodland extent is high (winner species).

4. This suggests that landscape context strongly mediates who wins and loses along agricultural intensity gradients. Likewise, where landscapes change, such as in deforestation frontiers, the very nature of the agriculture-biodiversity trade-offs can change as landscapes transformation progresses.

5. Synthesis and applications. Schemes to mitigate agriculture-biodiversity trade-offs, such as land sparing or sharing, must consider landscape context. Strategies that are identified based on a snapshot of data risk failure in dynamic landscapes, particularly where agricultural expansion continues to reduce natural habitats. Rather than a single, fixed strategy, adaptive management of agriculture-biodiversity 
trade-offs is needed in such situations. Here we provide a toolset for considering changing landscape contexts when exploring such trade-offs. This can help to better align agriculture and biodiversity in tropical and subtropical deforestation frontiers.

\section{KEYWORDS}

adaptive management, biodiversity loss, bird assemblages, deforestation frontiers, Gran Chaco, land-use intensity, multi-species occupancy, tropical dry forests and savannas

\section{$1 \mid$ INTRODUCTION}

Agriculture is a key driver of the ongoing biodiversity crisis (Kehoe et al., 2017; Maxwell, Fuller, Brooks, \& Watson, 2016), and how to best mitigate trade-offs between agriculture and biodiversity remains a major research challenge (Johnson et al., 2017). This question is particularly urgent for the world's tropical and subtropical forests, which host remarkable levels of biodiversity but are also an arena for widespread agricultural expansion and in tensification (Barlow et al., 2018). Understanding the fundamental relationship between biodiversity and agricultural intensity is central to solving this question (Tilman et al., 2017). The shape of the relationship between biodiversity and agricultural intensity determines which species benefit or lose out as agricultural intensification progresses. Analysing the trade-offs between biodiversity and agriculture can provide insight into whether separating intensive agriculture and areas for biodiversity (i.e. land sparing) or integrating them (i.e. land sharing) serves more species while producing the same amount of agricultural products (Green, Cornell, Scharlemann, \& Balmford, 2005). However, despite substantial theoretical and empirical research efforts into understanding the relationship between biodiversity and agricultural intensity (Newbold et al., 2015; Phalan, Onial, Balmford, \& Green, 2011), the question of how to best manage agriculture-biodiversity trade-offs in heterogeneous landscapes remains unresolved.

Many have argued that solutions to address these trade-offs must be context specific (Fischer et al., 2014; Grau, Kuemmerle, \& Macchi, 2013), but empirical evidence for this is very sparse (Gilroy, Edwards, Medina Uribe, Haugaasen, \& Edwards, 2014). Past assessments of trade-offs have typically adopted a bivariate approach, most often by assessing how the abundance of certain taxa varies across yield gradients. While such bivariate approaches can be helpful for environmental homogenous regions, it may ignore other factors known to influence biodiversity (Butsic et al., 2019; Grau et al., 2013). For instance, the extent of remaining natural habitat in the landscape is a key determinant of biodiversity (Fahrig, 2013; Fischer et al., 2014), as well as of species' ability to cope with agriculture (Mendenhall, Shields-Estrada, Krishnaswami, \& Daily, 2016). Likewise, both agriculture and biodiversity may vary across environmental gradients, such as temperature, aridity, soil quality (Houspanossian, Giménez, Baldi, \& Nosetto, 2016; Watson, 2011) or landscape heterogeneity (Macchi et al., 2019), and this can impact the relationship between biodiversity and agriculture (Butsic et al., 2019).

Understanding whether trade-offs between agriculture and biodiversity vary with landscape context, and how they interact with other environmental factors is critically important. To what extent can insights on trade-offs from a particular landscape be generalized to other settings? Are species consistently winners or losers of agricultural intensification, or does this depend on landscape context? Will strategies identified to mitigate trade-offs in a given landscape continue to work as these landscapes transform? Being able to answer such questions is crucial for identifying more sustainable development pathways for the world's tropical and subtropical deforestation frontiers. These are landscapes which are highly dynamic (Hansen et al., 2013), where biodiversity loss is particularly rapid (de Oliveira Roque et al., 2018), and where agriculture-biodiversity trade-offs are particularly high (Grau et al., 2013).

Here, we use a Bayesian hierarchical occupancy framework to explore how the trade-offs between agricultural intensity and biodiversity vary with changing landscape context. We focus on the South American Dry Chaco, an under-researched global deforestation hotspot (Kuemmerle et al., 2017). To explore the role of landscape context in shaping agriculture-biodiversity trade-offs at the species and community level, we rely on an extensive field dataset of bird occurrences (197 species, 234 survey plots) and agricultural intensity (measured in meat yield, energy yield and profit). Specifically, we ask:

1. How does the relationship between agricultural intensity and biodiversity vary across landscapes with different extents of remaining natural habitat?

2. Are agriculture-biodiversity trade-offs consistent across environmental gradients, and across different metrics used to characterize agricultural intensity?

\section{2 | MATERIALS AND METHODS}

\section{1 | Study area}

We focused on the Chaco Region in northern Argentina. The Dry Chaco is a subtropical dry forest with a highly seasonal climate and rainfall ranging between 400 and 800 mm annually (Minetti et al., 1999). 
Our study area encompassed about $190,000 \mathrm{~km}^{2}$, covering parts of Salta, Tucumán, Santiago del Estero, Chaco and Formosa Provinces (Figure 1). Natural vegetation is composed of a mosaic of semideciduous woodlands, savannas and grasslands. Woodlands are the most widespread land cover ( $70 \%$ of the region), and contain mainly xerophytic forest, as well as riparian forests. In addition, savannas and grasslands ( $7 \%$ of the region) occur in former river beds, on fire scars, on saline soils and in seasonally flooded areas (Baumann et al., 2017).

While the region has a long land-use history, large-scale conversion of the region's natural vegetation has happened only recently, especially after 2000 (Baumann et al., 2017). As a result, a range of dominant land uses juxtapose with different natural vegetation types, creating a diversity of land systems in the Chaco. These land systems can be arranged along an intensity gradient, from natural woodlands and grasslands without significant land use, across subsistence ranching, silvopastoral systems and implanted pastures to intensified cropping (mainly soybean, Figure 1; Table S1). Natural woodlands and grasslands are scarce today and predominantly occur inside protected areas. Subsistence ranching occurs widely inside woodlands and represents the land system with the lowest overall yields (Macchi, Grau, Zelaya, \& Marinaro, 2013). Silvopastures, where a part of the canopy (typically only the large trees) is retained and exotic grasses are sown underneath, have become particularly widespread since 2000 . Silvopastures range from very low woody cover $(<14 \%)$ to relatively high woody cover ( $>38 \%$, Macchi et al., 2019). Intensified pastures are likewise based on non-native grasses but do not retain trees. Finally, intensified croplands are used to cultivate a range of crops (e.g. maize, cotton and sorghum), but soybean production dominates. Overall, the expansion of intensified agriculture, both pastures for intensive cattle production and intensive soybean/maize systems, has triggered rapid and widespread woodland loss in the region (Grau, Aide, \& Gasparri, 2005).

\section{2 | Bird sampling}

We combined data from three extensive bird surveys in the study region (Decarre, 2015; Macchi et al., 2013; Mastrangelo \& Gavin, 2012; Figure 1). Birds were surveyed at 234 sites between 2009 and 2013 (see Appendix S1 in Supporting Information). Each site was sampled using point counts, where all individual birds were identified to the species level. Sites were arranged along a gradient of remaining natural vegetation. This allowed us to apply a space-for-time approach in which landscapes with different shares of remaining natural vegetation can be interpreted as temporal stages along a deforestation trajectory. This is justified for the Chaco, as the region was dominated by natural vegetation until the 1990s, but has since turned into a global deforestation hotspot (Baumann et al., 2017; Kuemmerle et al., 2017).

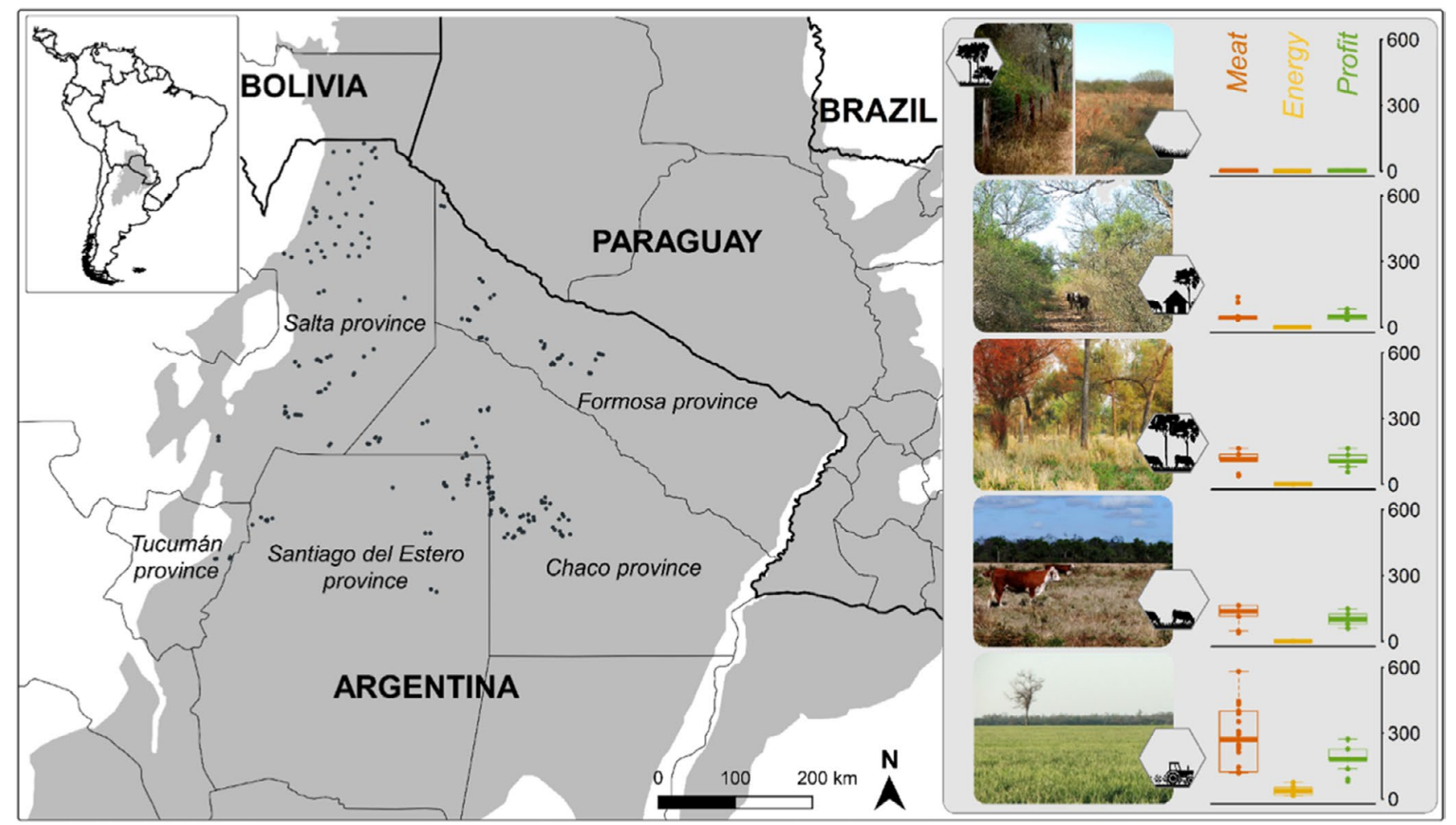

FIGURE 1 Study area in the northern Argentine Dry Chaco. Left: the Gran Chaco in South America (grey) and the bird sampling sites (black dots) distributed across the northern Argentine Dry Chaco. Right: land systems characterized by different agricultural intensity, from natural woodlands and grasslands to subsistence ranching, silvopasture, pasture and intensified croplands. Intensity, measured in yields, increase from top to bottom (meat in kg/ha*year; energy in GJ/ha*year and profit in USD/ha*year) 
Bird sampling sites were placed in all the main land systems in the region: 79 were located in natural woodlands, 16 in natural grasslands, 32 in subsistence ranching systems, 39 in silvopastoral systems, 27 in pasture systems and 41 in croplands. Sites located in the same type of land system were spatially separated by at least $0.5 \mathrm{~km}$ (Figure S1). Sampled land systems were distributed across the study area, and despite some were clustered regionally, land systems were generally well-interspersed (see methods in Decarre, 2015; Macchi et al., 2013; Mastrangelo \& Gavin, 2012). The unbalanced number of sample units roughly represents the distribution of these land systems in the Dry Chaco (Baumann et al., 2017). It is important to note that currently in the Dry Chaco natural grasslands are very scarce and only a few species occurred exclusively there in our study. Bird assemblages of woodlands and natural grasslands were thus considered as baseline communities, as they both share the condition of being largely undisturbed by human activities. Species accumulation curves suggest that all land systems and their associated bird assemblages were adequately represented in our dataset (Figure S2).

\section{3 | Agricultural intensity metrics}

Adequately addressing agricultural intensity and its impact on the environment requires considering the different dimensions of intensification (Kehoe et al., 2017). We measured agricultural intensity at all bird sampling sites using three metrics (a) meat yield (kg/ha*year); (b) energy yield (GJ/ha*year) and (c) profit (United State dollars USD/ha*year). While meat and energy yields are descriptors of agricultural production, profit is the variable more directly related to the farmers' expectations and decision-making (Jobbágy \& Sala, 2014).

We collected data on forage production along rainfall gradients for each land system, and estimated meat yield (secondary production) considering parameters of livestock systems destined to meat production in the Dry Chaco (Murray, Baldi, von Bernard, Viglizzo, \& Jobbágy, 2016). In the case of croplands, we considered soybean production, which was transformed to pork live weight (kg/ha*year) using a specific 5:1 conversion ratio (Smil, 2013). Next, we converted meat from livestock systems and grain from croplands into energy yield following standard conversion metrics (USDA, 2011). Finally, we applied a net-return econometric model (Murray et al., 2016) to translate meat production per land system to profit, considering the corresponding production and transportation costs related to each land system (for a full description of the estimation of the agricultural intensity metrics see Appendix S2).

The agricultural intensity gradient showed marked differences in the yield values when production increased from natural to intermediate and on to highly intensified production systems. For all the intensity metrics, croplands were the highest yielding system [mean values of meat: $260.2 \pm 51.3 S D$ (kg/ha*year); energy: $33.7 \pm 19.6 S D$ (GJ/ha*year); and profit: $189.9 \pm 55.2$ SD (USD/ha*year)], followed by silvopasture and pasture, and lastly the subsistence ranching system.
Natural woodland and grassland without livestock were assumed to have zero yields in all metrics (Figure 1; Table S1).

\section{4 | Landscape composition and environmental conditions}

We used covariates that reflected variation in landscape composition and environmental conditions within our study region. Considering the importance of habitat availability for determining species' occurrence (Fahrig, 2013), we calculated the woodland extent within buffers of 6 and $10 \mathrm{~km}$ around each sampling site (i.e. landscape spatial scale of c. 100 and $320 \mathrm{~km}^{2}$ respectively). To do this, we used forest cover maps from the Global Forest Change datasets (30-m resolution, Hansen et al., 2013) for the bird sampling corresponding year.

Water availability is one of the main environmental constraints for agriculture in the Chaco (Houspanossian et al., 2016). Thus, we calculated mean annual rainfall (hereafter: rainfall) and an aridity index (hereafter: aridity) for all bird sampling sites based on weather stations data by the National Institute of Agricultural Technology (INTA). We interpolated mean annual rainfall using geo-statistics (semi-variograms and kriging). The aridity was calculated dividing rainfall by evapotranspiration. Our covariates were generally only weakly correlated (Figure S3).

\section{5 | Occupancy modelling}

To assess the trade-off between avian biodiversity and agricultural intensity, we fitted trade-off curves between the two (Phalan et al., 2011). As a proxy for biodiversity, we estimated the probability of occupancy per species using a Bayesian framework (MacKenzie et al., 2006). Yet, occupancy models do not account for species' abundance as occupancy is solely based on whether a species is detected at a site. Occupancy models have some important advantages in this context. First, occupancy models account for imperfect detection, as some bird species may be more common or easier to detect than others. Second, occupancy models control for different sampling effort, observer identity, and sampling period among surveys as part of the detectability model (MacKenzie et al., 2006). Third, occupancy models allow for the consideration of multiple covariates when assessing the biodiversity versus agricultural intensity relationship (Kéry \& Royle, 2016). Finally, a Bayesian modelling framework allows for the simultaneous assessment of agriculture-biodiversity curves for the entire community and for each individual species.

We employed multi-species occupancy models under a Bayesian framework (Kéry \& Royle, 2016). To build the detection history, we used spatial replicates per site (nine for Macchi et al., 2013, six for Mastrangelo \& Gavin, 2012 and four for Decarre, 2015). The detectability model included the covariates survey (i.e. data source) and openness (i.e. categorical variable for the habitat type at the sampling site: woodland or open vegetation). We assessed bird occupancy as the response variable with seven possible covariates: three agricultural 
intensity metrics (meat yield, energy yield or profit), two landscape composition covariates (woodland extent for 6-km or 10-km buffers) and two environmental covariates (rainfall or aridity). In addition, each model included the interaction between the respective agricultural intensity metric and either woodland extent, rainfall or aridity, leading to a total of 24 different model combinations (Table S2). The interaction term allowed us to understand how the response of bird occupancy to agricultural intensity (e.g. meat yield) varied in relation to our environmental covariates (e.g. woodland extent). We fitted the models using only uncorrelated covariates (Figure S3), and considered a covariate to have a strong effect when the $95 \%$ credible interval of the parameter estimate (CRI) did not overlap zero. We compared all models using Watanabe-Akaike information criterion (WAIC; Watanabe, 2010), which is a useful model selection criterion for hierarchical models (Broms, Hooten, \& Fitzpatrick, 2016). Once we identified the best fitting model for the entire bird community, we examined this model in detail regarding responses at the species level. Specifically, we assessed the response curves for the 37 most common bird species (naïve occupancy of at least 10\%) that showed a strong effect of the meat yield $\times$ woodland extent interaction. More details on the occupancy modelling are provided in the Supporting Information, Appendix S3.

\section{3 | RESULTS}

Bird occupancy varied strongly across the land systems explored, from natural woodlands and grasslands to subsistence ranching, silvopastoral systems and intensified agriculture (pastures and cropping). Our best fitting occupancy model contained three covariates: meat yield as a measure of agriculture intensity, woodland extent as a measure of landscape composition (here: the share of forest and shrublands in a 10-km buffer around sampling sites) and aridity as a measure of environmental conditions, along with the interaction between meat yield and woodland extent. This model highlighted a strong, consistent and robust influence of woodland extent on the bird community as a whole [average occupancy across all species, $\hat{\beta}=0.25 ; 95 \%$ Bayesian credible intervals $(C R I)=(0.17,0.23)]$, and for most individual species (180 out of 197; Figure 2). At the community level, the effect of meat yield on bird occupancy was overall negative $[\hat{\beta}=-0.14 ; 95 \% \mathrm{CRI}=(-0.28,-0.19)]$. Importantly, the interaction between meat yield and woodland extent had a strong effect on the overall bird community $[\hat{\beta}=0.31 ; 95 \% \mathrm{CRI}=(0.24,0.29)$; Table S2]. Finally, the environmental conditions (i.e. aridity and rainfall in our models) had an overall weak effect on bird occupancy both at community and species levels $\left[\hat{\beta}_{\text {aridity }}=-0.004 ; 95 \% \mathrm{CRI}=(-0.084\right.$, -0.031); Figure S4].

The response of the bird community to agricultural intensity varied strongly with landscape context, as revealed by the strong interaction between meat yield and woodland extent (Figure 3). Community-level occupancy probability, which refers to the average occupancy across all species, declined rapidly towards zero with increasing agricultural intensity when woodland extent was

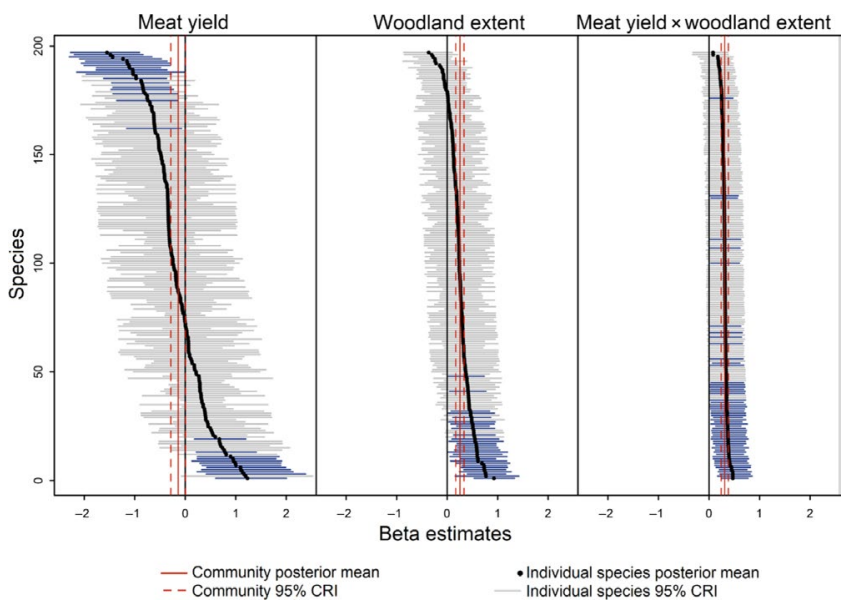

FIGURE 2 Effect of yield and woodland extent on the avian community occupancy. Coefficients (beta posterior means) of the best fitting model. Left: effect of agricultural intensity, measured in meat kg/ha*year. Middle: woodland extent measured as percentage forest cover in a 10-km buffer. Right: interaction of meat yield and woodland extent. The beta posterior mean (vertical red line for community and black dots for individual species) indicates how variation in the respective covariate influences bird occupancy. Individual species' Bayesian credible intervals (CRI) coloured in blue do not overlap zero

low (i.e. $2 \%-15 \%$ woodland extent, grey to yellow area in Figure 3). However, this was not the case when woodland extent was intermediate (i.e. $25 \%-50 \%$; orange to light green) or high (>50\%; dark green). In such situations, community-level occupancy was fairly constant or even increased with increasing agricultural intensity (Figure 3). Bird community occupancy was insensitive to increasing agricultural intensity beyond the threshold of $70 \%$ woodland extent in the 10-km surrounding landscape (Figure S5). Examining the average yields of some of the land systems in our study region further exemplifies this context dependency. Community-level occupancy varied by $8 \%$ in subsistence ranching systems (average meat yield $56.8 \pm 34.2 \mathrm{~kg} / \mathrm{ha}^{*}$ year), by $15.5 \%$ in silvopastoral systems (118.5 $\pm 28.1 \mathrm{~kg} / \mathrm{ha}^{*}$ year) and by $16 \%$ in pasture systems (125.6 $\pm 41.2 \mathrm{~kg} / \mathrm{ha}{ }^{*}$ year) depending on whether woodland extent was high or low. In the most intensified system (i.e. cropland, meat yield $=260.2 \pm 151.3 \mathrm{~kg} / \mathrm{ha}^{*}$ year, based on conversion to pork live weight), community-level occupancy ranged from $6 \%$ in sites with close to zero woodland to $30 \%$ if woodland extent was large (i.e. above 73\%, Figure 3). Similarly, woodland extent strongly mediated the response of individual bird species as well as the whole bird community to agricultural intensification for our two alternative measures of intensity, energy and profit (Figure 3).

Taking a closer look at the responses of individual bird species highlighted that many species changed fundamentally in their response to agricultural intensification as woodland extent changed. From the entire assemblage, we examined in detail the 37 most common bird species (naïve occupancy of at least 10\%) that had a strong response to the meat yield $\times$ woodland extent interaction (see Section 2, Figure S6; Table S3). Three out of these 37 most 

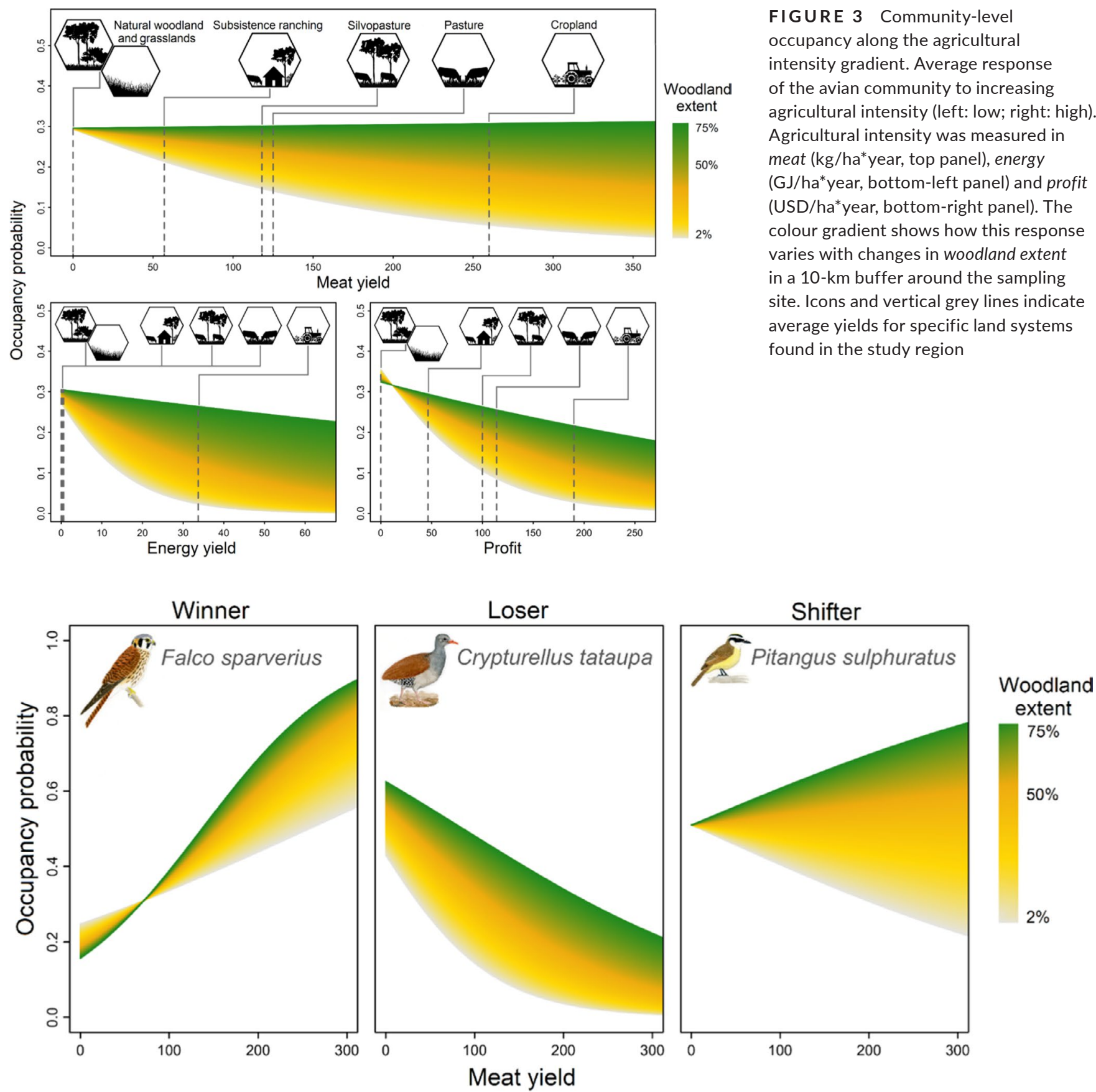

FIGURE 4 Individual species' responses to agricultural intensity, depending on woodland extent in the landscape. Left: winner species have consistently increasing occupancy as agricultural intensity increases (example: American Kestrel). Note the beneficial effect of woodland extent where agricultural intensification is higher (green colour vs. yellow colour). Middle: loser species are consistently negatively impacted by agricultural intensification, but this effect is weaker in landscapes with more woodland (example: Tataupa Tinamou). Right: shifter species respond either negatively to agricultural intensity where woodland extent is low (yellow colour) or benefit from agricultural intensification where woodland extent is high (example: Great Kiskadee)

common species consistently benefitted from agricultural intensification with a sustained occupancy increase along the gradient, and we refer to these species as winner species. Although always winners, the beneficial effect of intensification for winner species was stronger in landscapes with higher woodland extent (e.g. the American Kestrel Falco sparverius in Figure 4). Twelve out of the 37 common species were consistently negatively affected by increasing
FIGURE 3 Community-level occupancy along the agricultural intensity gradient. Average response of the avian community to increasing agricultural intensity (left: low; right: high). Agricultural intensity was measured in meat (kg/ha*year, top panel), energy (GJ/ha*year, bottom-left panel) and profit (USD/ha*year, bottom-right panel). The colour gradient shows how this response varies with changes in woodland extent in a 10-km buffer around the sampling site. Icons and vertical grey lines indicate average yields for specific land systems found in the study region 
occupancy probability depended on woodland extent (Figure S6). Such species were losers in landscapes with low woodland extent, yet winners in landscapes where woodland extent was high (e.g. the Great Kiskadee Pitangus sulphuratus, Figure 4). We refer to such species as 'shifter species' as their responses changed from winner to loser as woodland extent decreased (see Supporting Information for a detailed breakdown of the responses of all 37 species, specifically in Figure S6; Table S3).

\section{4 | DISCUSSION}

Forests in the Global South are among the fiercest battlegrounds for conservation, as agricultural expansion and intensification accelerate (Barlow et al., 2018). Understanding how biodiversity responds to intensifying agriculture in such regions is key to finding land-use strategies that effectively mitigate the drastic trade-offs between the two (Grau et al., 2013). Assessments of these trade-offs often rely on agricultural intensity versus biodiversity curves (Green et al., 2005), assuming that these trade-off curves do not change and can thus be generalized in time and space. Our first research question sought to understand how these curves vary across landscapes with different extents of remaining natural habitat, focusing on the Argentinean Chaco, a global deforestation hotspot. We show that the assumption of static trade-off curves is not always warranted. Both the shape and the fundamental nature of trade-off curves can vary dramatically across landscapes with different levels of remaining woodlands, which in our case represent different stages along the deforestation trajectory. In the Chaco, many species changed drastically in their response to increasing agricultural intensity, from being winners of intensification in landscapes that still contain sizable areas of woodland, to being losers in landscapes where woodlands are scarce. Strategies aimed at aligning agriculture and biodiversity must, therefore, consider landscape context to avoid unwanted outcomes and ineffective policies.

This is particularly relevant for tropical and subtropical deforestation frontiers, where landscape context is changing rapidly. For instance, agricultural expansion has resulted in 50\% of Borneo's native forests being cut down since 1930 (McAlpine et al., 2018), more than $20 \%$ of the Amazonian forests converted to pastures and cropland since 1990 (Khanna, Medvigy, Fueglistaler, \& Walko, 2017), and rising deforestation rates in the Congo Basin (Tegegne, Lindner, Fobissie, \& Kanninen, 2016). Dry forests and savannas are particularly hard-hit by agricultural expansion, with almost half of the Cerrado converted to cropland (Strassburg et al., 2017), most of the tropical dry forest of Madagascar destroyed (Vieilledent et al., 2018) and deforestation rates in the Dry Chaco among the world's highest (Baumann et al., 2017). Our results suggest that this conversion of natural habitat to agriculture strongly determines how biodiversity reacts to agricultural intensification, including which species win or lose. This finding, robust across different intensity metrics, is in line with recent work highlighting the importance of remaining natural habitat (De Camargo, Boucher-Lalonde, \& Currie, 2018;
Fahrig, 2013), particularly in landscapes that were historically forest dominated (Mendenhall et al., 2016). Our finding that the impact of intensification is overall less negative, and sometimes even positive, in landscapes with sizeable areas of remaining woodland thus provides further arguments for ramping up the protection of natural habitat (e.g. Half Earth and Aichi Biodiversity Targets Initiatives, Watson \& Venter, 2017).

Important cross-scale interactions regarding the relationship of agricultural intensity and biodiversity emerged in our case. At the local scale, the impact of agricultural intensification on the bird community in the Dry Chaco was mostly negative (64\% of all species responded negatively) and nonlinear, with a rapid decline in occupancy between natural vegetation and intermediate-yielding land systems. This is well in line with prior work from the Chaco (Decarre, 2015; Macchi et al., 2013; Mastrangelo \& Gavin, 2012), from other tropical regions (Dotta, Phalan, Silva, Green, \& Balmford, 2015; Phalan et al., 2011), and from global-scale meta-analyses (Newbold et al., 2015). Yet, at the landscape scale, this trade-off was strongly and consistently mediated by woodland extent, to which $91 \%$ of all species responded positively. Three main conclusions derive from this finding. First, there is likely to be some potential for intensifying agriculture at a relatively low cost for biodiversity, but only if enough woodland remains in the landscape. However, we strongly caution that biodiversity loss can be drastic if these remaining woodlands are subsequently converted, even if agricultural intensity stays constant, as exemplified by the many shifter species we found (Figure S6). Similar results were found for Colombia where 'sharing' species, which can benefit from low-intensity agriculture such as shadecoffee plantations, disappear from the agricultural matrix away from large forest patches (Gilroy, Edwards, Medina Uribe, Haugaasen, \& Edwards, 2014). Second, considering individual species' response to agricultural intensity is key for designing sustainable landscapes. For instance, some species were consistently losers regardless of the woodland extent; these species require unaltered natural habitats (Table S3). Third, trade-off assessments should explicitly consider both local and regional scales (Torrella et al., 2018). Few past studies have looked at the role of landscape composition surroundings to determine agriculture-biodiversity trade-offs. Here, we consider this aspect by combining field-based, plot-level data of bird occurrences and yields with landscape composition.

Our second research question asked whether agriculturebiodiversity trade-offs are consistent across environmental gradients and across different agricultural intensity metrics. We had expected that environmental factors, especially the strong aridity gradient characterizing the Chaco, would impact the shape of agriculturebiodiversity trade-off curves. Surprisingly, this was not the case for either rainfall or aridity (Figure S4; Table S2). A possible explanation is that aridity is not a limiting factor for birds in the Chaco, likewise other taxa in this dry forest (Alonso, Zurita, \& Bellocq, 2020; Torres, Gasparri, Blendinger, \& Grau, 2014). We found similar results whichever metric of agricultural intensity we used, in accordance with other work on agriculture-biodiversity trade-offs focusing on bird communities in the Eurasian steppes (Kamp et al., 2015). In 
summary, our main finding that agriculture-biodiversity trade-offs vary considerably with landscape context, as measured by the share of remaining woodland, was consistent across the environmental gradient and a range of agricultural intensity metrics.

For land-use and conservation planning in the Chaco, our study translates into a number of concrete recommendations. First, the extent of strictly protected remaining natural habitat in the Chaco should be increased substantially (currently $<1 \%$ in our study region, $9 \%$ for the Chaco as a whole). Occupancy levels of most species (91\%) were positively related to woodland extent in our study (Figure 2). Moreover, most species were less impacted by agricultural intensification, or even benefitted from it, if large areas of woodlands remained in the surrounding landscape (Table S3). We note that there are also species of conservation concern that require more open landscapes, and this should be adequately considered in conservation planning. Second, land systems with low and intermediate agricultural intensity can still provide substantial conservation value (Table S1). Less intensive production systems (e.g. silvopastures vs. intensified pastures) do raise woody cover at the landscape scale and thus can mitigate some of the negative effects of agricultural intensification on biodiversity (Macchi et al., 2019; Mastrangelo \& Gavin, 2012). Our analyses also clearly suggest that landscape planning that promotes highly intensified production alongside remaining woodlands makes such landscapes highly vulnerable to future biodiversity loss, if woodlands continue to be converted. Third, the biodiversity impact of even the most intensive agricultural systems can be mitigated substantially if major tracts of woodland are preserved. For instance, when keeping woodland extent in the landscape above $70 \%$, the community occupancy did not change strongly with increasing agricultural intensity, and maintaining a woodland extent of $50 \%$ kept about $80 \%$ of the biodiversity in intensified ranching systems (Figure 3; Figure S5). Overall, these findings suggest that pure land sharing or sparing strategies might not be truly optimal. Instead, mixes of land systems of varying intensities could strike a better balance between agriculture and biodiversity (Butsic et al., 2019). As new tools for identifying such optimal landscapes emerge (Law et al., 2017; Moilanen, Leathwick, \& Quinn, 2011), assessing which combinations and configurations of land systems can simultaneously produce and maintain biodiversity and multiple ecosystems services would result in an interesting line of research (Triviño et al., 2017).

While we analysed the effect of landscape context in terms of composition, we did not assess the possible impact of configuration (e.g. fragmentation level, number of patches) on bird occupancy patterns. From landscape to regional scales, the effect of habitat fragmentation appears to be small compared to the effect of habitat amount (De Camargo et al., 2018; Fahrig, 2013), but this requires further investigation. Likewise, we grouped several natural vegetation types into our woodland category, although there is heterogeneity between them (e.g. due to soil types or rainfall patterns; Grau et al., 2005), and woodland quality might differ due to varying land-use history (Baumann et al., 2017). In addition, we did not account for other anthropogenic determinants of bird occupancy, such as hunting. While for most birds in the Chaco this is not a major issue, hunting can be a main determinant of species' abundance for other taxa in the Chaco, such as mammals (Altrichter, 2005; Romero-Muñoz et al., 2020). One possible limitation of using the space-for-time approach is that our results might include the effect of extinction debt, which has been suggested to exist in the Chaco (Semper-Pascual et al., 2018). If extinction debt currently exists in the Chaco and were to be paid, then the contrast between high-intensity systems and our natural baseline systems would weaken as habitat specialists would be lost and remaining bird species in the landscape would more likely be habitat generalists. It is reasonable to assume that this would lead to a stronger signal in regard to our main finding: that woodland extent mediates the agriculture-biodiversity tradeoff substantially, and that considerable shares of woodland are needed to sustain a diverse bird assemblage. Finally, we only considered the biodiversity impacts of agricultural production, but did not consider other important environmental outcomes such as water pollution, soil degradation and greenhouse gas emissions. Similarly, we did not consider important social factors such as equity, poverty, employment or health, all of which differ across our land systems. Understanding and exploring how these elements interact with biodiversity and agricultural production are necessary next steps to derive holistic recommendations about sustainable land systems in the Chaco.

Here we show that the agriculture-biodiversity trade-offs vary as agricultural expansion transforms landscapes, and are thus a moving target. The current practice of not accounting for changing landscape context could be potentially devastating: land-use strategies found optimal at one point in time could be suboptimal or even detrimental if the landscape changes in the future. Accounting for the potentially dynamic relationship between biodiversity and agriculture is particularly important in tropical and subtropical deforestation frontiers, which harbour astonishing biodiversity, which are changing rapidly, and which are arguably in critical need of effective land use and conservation planning. In dynamic landscapes such as these, an adaptive strategy is needed to analyse and manage tradeoffs between agriculture and biodiversity. Here we provide a toolset for explicitly exploring trade-offs across scales, which can help to avoid surprising and unwanted outcomes. Rather than identifying a fixed land-use strategy, understanding which mixes of land systems align agriculture and biodiversity best at broader scales, now and under future conditions, should be key goals for scientists and decision-makers.

\section{ACKNOWLEDGEMENTS}

We gratefully acknowledge funding by the German Ministry of Education and Research (BMBF, project PASANOA, 031B0034A), the German Research Foundation (DFG, project KU 2458/5-1), the Argentine Fund for Scientific and Technological Research (FONCYT, project PICT 2006-1693), the INTA Natural Resources National Programme (project PNNAT 1128053 and 1128052) and the Alexander von Humboldt Foundation. We also thank Claire Wordley for very valuable comments and language revisions, and Serge Nicolle for authorizing the use of his drawings in Figure 4. We are 
grateful to the Associate Editor G. Peralta and two anonymous reviewers for helpful and constructive comments on prior manuscript versions.

\section{AUTHORS' CONTRIBUTIONS}

L.M., J.D. and T.K. designed the research; L.M., M.M., J.D. and P.G.B. collected field data; A.S.-P., M.P.R. and F.M. prepared spatial data and contributed to the modelling; A.P.G. analysed the data; J.D. and A.P.G. designed the figures; L.M., J.D., A.P.G., M.M., P.G.B., G.I.G.-P., F.M., M.P.-R., A.S.-P. and T.K. wrote the paper. All the authors approved the publication of this paper.

\section{DATA AVAILABILITY STATEMENT}

Data available via the Dryad Digital Repository https://doi.org/ 10.5061/dryad.msbcc2fvt (Macchi et al., 2020).

\section{ORCID}

Leandro Macchi iD https://orcid.org/0000-0002-1589-038X Asunción Semper-Pascual iD https://orcid.org/0000-0001-7376-9214

\section{REFERENCES}

Alonso, C. B., Zurita, G. A., \& Bellocq, M. I. (2020). Dung beetles response to livestock management in three different regional contexts. Scientific Reports, 10(1), 1-10.

Altrichter, M. (2005). The sustainability of subsistence hunting of peccaries in the Argentine Chaco. Biological Conservation, 126, 351-362. https://doi.org/10.1016/j.biocon.2005.06.024

Barlow, J., França, F., Gardner, T. A., Hicks, C. C., Lennox, G. D., Berenguer, E., ... Graham, N. A. J. (2018). The future of hyperdiverse tropical ecosystems. Nature, 559(7715), 517-526. https://doi.org/10.1038/ s41586-018-0301-1

Baumann, M., Gasparri, N. I., Piquer-Rodríguez, M., Gavier-Pizarro, G. I., Griffiths, P., Hostert, P., \& Kuemmerle, T. (2017). Carbon emissions from agricultural expansion and intensification in the Chaco. Global Change Biology, 23, 1902-1916. https://doi.org/10.1111/gcb. 13521

Broms, K. M., Hooten, M. B., \& Fitzpatrick, R. M. (2016). Model selection and assessment for multi-species occupancy models. Ecology, 97(7), 1759-1770. https://doi.org/10.1890/15-1471.1

Butsic, V., Kuemmerle, T., Pallud, L., Helmstedt, K. J., Macchi, L., \& Potts, M. D. (2019). Aligning biodiversity conservation and agricultural production in heterogeneous landscapes. Ecological Applications, 30(3), 2057. https://doi.org/10.1002/eap.2057

De Camargo, R. X., Boucher-Lalonde, V., \& Currie, D. J. (2018). At the landscape level, birds respond strongly to habitat amount but weakly to fragmentation. Diversity and Distributions, 24, 629-639. https:// doi.org/10.1111/ddi.12706

de Oliveira Roque, F., Menezes, J. F. S., Northfield, T., Ochoa-Quintero, J. M., Campbell, M. J., \& Laurance, W. F. (2018). Warning signals of biodiversity collapse across gradients of tropical forest loss. Scientific Reports, 8(1), 1622. https://doi.org/10.1038/s41598-01819985-9

Decarre, J. (2015). Diversity and structure of bird and mammal communities in the Semiarid Chaco Region: Response to agricultural practices and landscape alterations. Imperial College London. https://doi. org $/ 10.25560 / 38615$

Dotta, G., Phalan, B., Silva, T. W., Green, R. E., \& Balmford, A. (2015). Assessing strategies to reconcile agriculture and bird conservation in the temperate grasslands of South America. Conservation Biology, 30(3), 618-627. https://doi.org/10.1111/cobi.12635
Fahrig, L. (2013). Rethinking patch size and isolation effects: The habitat amount hypothesis. Journal of Biogeography, 40(9), 1649-1663. https://doi.org/10.1111/jbi.12130

Fischer, J., Abson, D. J., Butsic, V., Chappell, M. J., Ekroos, J., Hanspach, J., ... Von Wehrden, H. (2014). Land sparing versus land sharing: Moving forward. Conservation Letters, 7(3), 149-157. https://doi.org/ 10.1111/conl.12084

Gilroy, J. J., Edwards, F. A., Medina Uribe, C. A., Haugaasen, T., \& Edwards, D. P. (2014). EDITOR'S CHOICE: Surrounding habitats mediate the trade-off between land-sharing and land-sparing agriculture in the tropics. Journal of Applied Ecology, 51(5), 1337-1346. https://doi. org/10.1111/1365-2664.12284

Grau, H. R., Aide, T. M., \& Gasparri, N. I. (2005). Globalization and soybean expansion into semiarid ecosystems of Argentina. Ambio, 34(3), 265-266. https://doi.org/10.1579/0044-7447-34.3.265

Grau, H. R., Kuemmerle, T., \& Macchi, L. (2013). Beyond 'land sparing versus land sharing': Environmental heterogeneity, globalization and the balance between agricultural production and nature conservation. Current Opinion in Environmental Sustainability, 5(5), 477-483. https://doi.org/10.1016/j.cosust.2013.06.001

Green, R. E., Cornell, S. J., Scharlemann, J. P. W., \& Balmford, A. (2005). Farming and the fate of wild nature. Science, 307(5709), 550-555. https://doi.org/10.1126/science.1106049

Hansen, M. C., Potapov, P. V., Moore, R., Hancher, M., Turubanova, S. A., Tyukavina, A., ... Townshend, J. R. G. (2013). High-resolution global maps of 21st-century forest cover change. Science, 342, 850-853. https://doi.org/10.1126/science.1244693

Houspanossian, J., Giménez, R., Baldi, G., \& Nosetto, M. (2016). Is aridity restricting deforestation and land uses in the South American Dry Chaco? Journal of Land Use Science, 4248(February), 1-17. https://doi. org/10.1080/1747423X.2015.1136707

Jobbágy, E. G., \& Sala, O. E. (2014). The imprint of crop choice on global nutrient needs. Environmental Research Letters, 9(8), https://doi. org/10.1088/1748-9326/9/8/084014

Johnson, C. N., Balmford, A., Brook, B. W., Buettel, J. C., Galetti, M., Guangchun, L., \& Wilmshurst, J. M. (2017). Biodiversity losses and conservation responses in the Anthropocene. Science, 356(6335), 270-275. https://doi.org/10.1126/science.aam9317

Kamp, J., Urazaliev, R., Balmford, A., Donald, P. F., Green, R. E., Lamb, A. J., \& Phalan, B. (2015). Agricultural development and the conservation of avian biodiversity on the Eurasian steppes: A comparison of land-sparing and land-sharing approaches. Journal of Applied Ecology, 52(6), 1578-1587. https://doi.org/10.1111/1365-2664.12527

Kehoe, L., Romero-Muñoz, A., Polaina, E., Estes, L., Kreft, H., \& Kuemmerle, T. (2017). Biodiversity at risk under future cropland expansion and intensification. Nature Ecology \& Evolution, 1(8), 11291135. https://doi.org/10.1038/s41559-017-0234-3

Kéry, M., \& Royle, J. A. (2016). Applied hierarchical modeling in ecology: Analysis of distribution. Abundance and species richness in $R$ and BUGS (Vol. 1, 1st ed.). London, UK: Elsevier Academic Press.

Khanna, J., Medvigy, D., Fueglistaler, S., \& Walko, R. (2017). Regional dry-season climate changes due to three decades of Amazonian deforestation. Nature Climate Change, 7(3), 200-204. https://doi. org/10.1038/nclimate3226

Kuemmerle, T., Altrichter, M., Baldi, G., Cabido, M., Camino, M., Cuellar, E., ... Zak, M. (2017). Forest conservation: Remember Gran Chaco. Science, 355(6324), 465. https://doi.org/10.1126/science. aal3020

Law, E. A., Bryan, B. A., Meijaard, E., Mallawaarachchi, T., Struebig, M. J., Watts, M. E., \& Wilson, K. A. (2017). Mixed policies give more options in multifunctional tropical forest landscapes. Journal of Applied Ecology, 54(1), 51-60. https://doi.org/10.1111/1365-2664.12666

Macchi, L., Baumann, M., Bluhm, H., Baker, M., Levers, C., Grau, H. R., \& Kuemmerle, T. (2019). Thresholds in forest bird communities along woody vegetation gradients in the South American Dry 
Chaco. Journal of Applied Ecology, 56, 629-639. https://doi.org/ 10.1111/1365-2664.13342

Macchi, L., Decarre, J., Goijman, A. P., Mastrangelo, M., Blendinger, P. G., Gavier-Pizarro, G. I., ... Kuemmerle, T. (2020). Data from: Trade-offs between biodiversity and agriculture are moving targets in dynamic landscapes. Dryad Digital Repository, https://doi.org/10.5061/dryad. msbcc2fvt

Macchi, L., Grau, H. R., Zelaya, P. V., \& Marinaro, S. (2013). Trade-offs between land use intensity and avian biodiversity in the dry Chaco of Argentina: A tale of two gradients. Agriculture, Ecosystems \& Environment, 174, 11-20.

MacKenzie, D. I., Nichols, J. D., Yoccoz, N. G., Royle, J. A., Pollock, K. H., Bailey, L. L., \& Hines, J. E. (2006). Occupancy Estimation and Modeling: Inferring patterns and dynamics of species occurrence. Elsevier Academic Press. https://doi.org/10.1017/CBO9781107415324.004

Mastrangelo, M. E., \& Gavin, M. C. (2012). Trade-offs between cattle production and bird conservation in an agricultural frontier of the Gran Chaco of Argentina. Conservation Biology, 26(6), 1040-1051. https://doi.org/10.1111/j.1523-1739.2012.01904.x

Maxwell, S. L., Fuller, R. A., Brooks, T. M., \& Watson, J. E. M. (2016). Biodiversity: The ravages of guns, nets and bulldozers. Nature, 536(7615), 143-145. https://doi.org/10.1038/536143a

McAlpine, C. A., Johnson, A., Salazar, A., Syktus, J., Wilson, K., Meijaard, E., ... Sheil, D. (2018). Forest loss and Borneo's climate. Environmental Research Letters, 13(4), 044009. https://doi.org/10.1088/1748-9326/ aaa4ff

Mendenhall, C. D., Shields-Estrada, A., Krishnaswami, A. J., \& Daily, G. C. (2016). Quantifying and sustaining biodiversity in tropical agricultural landscapes. Proceedings of the National Academy of Sciences of the United States of America, 113(51), 14544-14551. https://doi. org/10.1073/pnas.1604981113

Minetti, J. L., Albarracín, S. A., Bobba, M. E., Hernández, C. M., López, E. R., Acuña, L. A., \& Mendoza, E. (1999). Atlas climático del noroeste argentino. San Miguel de Tucumán, Argentina: Fundacion Caldenius.

Moilanen, A., Leathwick, J. R., \& Quinn, J. M. (2011). Spatial prioritization of conservation management. Conservation Letters, 4(5), 383-393. https://doi.org/10.1111/j.1755-263X.2011.00190.x

Murray, F., Baldi, G., von Bernard, T., Viglizzo, E. F., \& Jobbágy, E. G. (2016). Productive performance of alternative land covers along aridity gradients: Ecological, agronomic and economic perspectives. Agricultural Systems, 149, 20-29. https://doi.org/10.1016/j. agsy.2016.08.004

Newbold, T., Hudson, L. N., Hill, S. L. L., Contu, S., Lysenko, I., Senior, R. A., ... Purvis, A. (2015). Global effects of land use on local terrestrial biodiversity. Nature, 520, 45-50. https://doi.org/10.1038/nature 14324

Phalan, B., Onial, M., Balmford, A., \& Green, R. E. (2011). Reconciling food production and biodiversity conservation: Land sharing and land sparing compared. Science, 333(September), 1289-1291. https://doi. org/10.1126/science.1208742

Romero-Muñoz, A., Benítez-López, A., Zurell, D., Baumann, M., Camino, M., Decarre, J., ... Kuemmerle, T. (2020). Increasing synergistic effects of habitat destruction and hunting on mammals over three decades in the Gran Chaco. Ecography, 43, 1-13. https://doi.org/10.1111/ ecog.05053

Semper-Pascual, A., Macchi, L., Sabatini, F. M., Decarre, J., Baumann, M., Blendinger, P. G., ... Kuemmerle, T. (2018). Mapping extinction debt highlights conservation opportunities for birds and mammals in the South American Chaco. Journal of Applied Ecology, 55(3), 1218-1219. https://doi.org/10.1111/1365-2664.13074
Smil, V. (2013). Should we eat meat. Evolution and consequences of modern carnivory. New York, NY: Wiley-Blackwell.

Strassburg, B. B. N., Brooks, T., Feltran-Barbieri, R., Iribarrem, A., Crouzeilles, R., Loyola, R., ... Balmford, A. (2017). Moment of truth for the Cerrado hotspot. Nature Ecology \& Evolution, 1(4), 1-3. https:// doi.org/10.1038/s41559-017-0099

Tegegne, Y. T., Lindner, M., Fobissie, K., \& Kanninen, M. (2016). Evolution of drivers of deforestation and forest degradation in the Congo Basin forests: Exploring possible policy options to address forest loss. Land Use Policy, 51, 312-324. https://doi.org/10.1016/j.landusepol.2015.11.024

Tilman, D., Clark, M., Williams, D. R., Kimmel, K., Polasky, S., \& Packer, C. (2017). Future threats to biodiversity and pathways to their prevention. Nature, 546(7656), 73-81. https://doi.org/10.1038/nature 22900

Torrella, S. A., Piquer-Rodríguez, M., Levers, C., Ginzburg, R. G., GavierPizarro, G. I., \& Kuemmerle, T. (2018). Multiscale spatial planning to maintain forest connectivity in the Argentine Chaco in the face of deforestation. Ecology and Society, 23(4), 37. https://doi.org/10.5751/ ES-10546-230437

Torres, R., Gasparri, N. I., Blendinger, P. G., \& Grau, H. R. (2014). Landuse and land-cover effects on regional biodiversity distribution in a subtropical dry forest: A hierarchical integrative multi-taxa study. Regional Environmental Change, 14(4), 1549-1561. https://doi. org/10.1007/s10113-014-0604-1

Triviño, M., Pohjanmies, T., Mazziotta, A., Juutinen, A., Podkopaev, D., Le Tortorec, E., \& Mönkkönen, M. (2017). Optimizing management to enhance multifunctionality in a boreal forest landscape. Journal of Applied Ecology, 54(1), 61-70. https://doi.org/10.1111/1365-2664. 12790

USDA. (2011). National nutrient database for standard reference: Release 14. Washington, DC: Department of Agriculture, Agricultural Research Service. Food Data Central.

Vieilledent, G., Grinand, C., Rakotomalala, F. A., Ranaivosoa, R., Rakotoarijaona, J., Allnutt, T. F., \& Achard, F. (2018). Combining global tree cover loss data with historical national forest cover maps to look at six decades of deforestation and forest fragmentation in Madagascar. Biological Conservation, 222(January), 189-197. https:// doi.org/10.1016/j.biocon.2018.04.008

Watanabe, S. (2010). Asymptotic equivalence of Bayes cross validation and widely applicable information criterion in singular learning theory. Journal of Machine Learning Research, 11, 3571-3594.

Watson, D. M. (2011). A productivity-based explanation for woodland bird declines: Poorer soils yield less food. Emu - Austral Ornithology, 111(1), 10-18. https://doi.org/10.1071/MU09109

Watson, J. E. M., \& Venter, O. (2017). A global plan for nature conservation. Nature, 550(7674), 48-49. https://doi.org/10.1038/nature 24144

\section{SUPPORTING INFORMATION}

Additional supporting information may be found online in the Supporting Information section.

How to cite this article: Macchi L, Decarre J, Goijman AP, et al. Trade-offs between biodiversity and agriculture are moving targets in dynamic landscapes. J Appl Ecol. 2020;00:1-10. https://doi.org/10.1111/1365-2664.13699 